\title{
Imprecisão orçamentária das receitas e despesas públicas dos municípios das Regiões Imediatas de Teófilo Otoni e Águas Formosas - MG entre os exercícios financeiros de
}

\section{3-2018}

\author{
Budgetary inaccuracy of public revenues and expenses of the municipalities of the Immediate \\ Regions of Teófilo Otoni and Águas Formosas - MG between the financial years 2013-2018
}

Inexactitud presupuestaria de los ingresos y gastos públicos de los municipios de lãs Regiones Inmediatas de Teófilo Otoni y Águas Formosas - MG entre los ejercicios 2013-2018

Recebido: 06/09/2021 | Revisado: 12/09/2021 | Aceito: 30/09/2021 | Publicado: 02/10/2021

\author{
Rosenália Ramalho Teixeira \\ ORCID: https://orcid.org/0000-0003-1407-5890 \\ Universidade Federal dos Vales do Jequitinhonha e Mucuri, Brasil \\ E-mail: rosenalia.teixeira@ufvjm.edu.br \\ Vasconcelos Reis Wakim \\ ORCID: https://orcid.org/0000-0002-0401-0180 \\ Universidade Federal dos Vales do Jequitinhonha e Mucuri, Brasil \\ E-mail: vasconcelos.wakim@ufvjm.edu.br \\ Geórgia Fernandes Barros \\ ORCID: https://orcid.org/0000-0003-1362-9548 \\ Universidade Federal dos Vales do Jequitinhonha e Mucuri, Brasil \\ E-mail: georgia.barros@ufvjm.edu.br \\ Agnaldo Keiti Higuch \\ ORCID: https://orcid.org/0000-0001-8719-6154 \\ Universidade Federal dos Vales do Jequitinhonha e Mucuri, Brasil \\ E-mail: Agnaldo.higuchi@ufvjm.edu.br \\ Raquel Cristina Lucas Mota \\ ORCID: https://orcid.org/0000-0003-1543-4306 \\ Universidade Federal dos Vales do Jequitinhonha e Mucuri, Brasil \\ E-mail: raquel.lucasmota@ufvjm.edu.br \\ Henrique Rosario Carvalho Esteves \\ ORCID: https://orcid.org/0000-0002-5927-0131 \\ Universidade Federal dos Vales do Jequitinhonha e Mucuri, Brasil \\ E-mail: henriqueestevesccb@hotmail.com
}

\begin{abstract}
Resumo
A pesquisa aborda os instrumentos orçamentários que conduzem à identificação da imprecisão orçamentária no contexto da Gestão Financeira Pública. Nesta perspectiva, é possível destacar o planejamento, o orçamento público, os relatórios de receitas e despesas públicos, o PPA, a LDO e a LOA. O objetivo consiste em verificar a imprecisão orçamentária entre os valores previstos e realizados de arrecadação de receitas e despesas públicas dos municípios das Regiões Imediatas de Teófilo Otoni e Águas Formosas - MG entre os exercícios financeiros de 2013-2018 e classificá-los segundo a sua efetividade. Os dados coletados junto ao site do Tribunal de Contas do Estado de Minas Gerais (TCE-MG) foram organizados em planilhas de Dados em Painel balanceado, com Modelo de Efeitos Fixos. Foram utilizadas para a classificação das variáveis dummies as notas do I-Planejamento e I-Fiscal que compõem o IEGM-TCEMG e para mensurar o nível da imprecisão dos municípios, aplicou-se a classificação do programa PEFA. Os Resultados evidenciaram que conforme classificação do PEFA, a maioria dos municípios podem ser considerados imprecisos, tanto nas receitas, quanto para as despesas, recebendo a pior nota do programa conceituada pela letra D. Verificou-se também que na estimação econométrica a variável independente população e as dummies foram significativas para explicar essa imprecisão.
\end{abstract}

Palavras-chave: Planejamento público; Imprecisão orçamentária; Receitas e despesas públicas.

\section{Abstract}

The research addresses the budgetary instruments that lead to the identification of budgetary imprecision in the context of Public Financial Management. In this perspective, it is possible to highlight the planning, the public budget, the public revenue and expenditure reports, and the PPA (budgetary multi-year plan), the LDO (bugdet guidelines law) and the LOA (annual budgetary law). The objective is to verify the budgetary inaccuracy between the estimated 
and the concretized amounts of public revenue collection and expenditure in the municipalities of the Immediate Regions of Teófilo Otoni and Águas Formosas, Minas Gerais state, between the 2013 and 2018 financial years and classify them according to their effectiveness. The data collected from the website of the Court of Auditors of the State of Minas Gerais (TCE-MG) were organized in balanced Panel Data spreadsheets, with a Fixed Effects Model. The scores from the I-Planejamento (a budgetary planning index) and I-Fiscal (a tax collection index) that make up the IEGM-TCEMG (Municipal Management Effectiveness Index by the TCE-MG) were used to classify the dummy variables; and to measure the level of inaccuracy of the municipalities, the classification of the PEFA program was applied. The results showed that, according to the PEFA classification, most municipalities can be considered inaccurate, both in terms of revenue and expenditure, receiving the worst score in the program, conceptualized by the letter D. It was also found that in the econometric estimation, the independent variable "Population" and the dummy variables were significant in explaining this inaccuracy.

Keywords: Public planning; Budgetary imprecision; Public revenues and expenses.

\section{Resumen}

La investigación aborda los instrumentos presupuestarios que conducen a la identificación de la imprecisión presupuestaria en el contexto de la Gestión Financiera Pública. En esta perspectiva, es posible destacar la planificación, el presupuesto público, los informes de ingresos y gastos públicos, y el PPA (plan plurianual presupuestario), el LDO (ley de pautas presupuestarias) y el LOA (ley de presupuesto anual). El objetivo es verificar la inexactitud presupuestaria entre los montos estimados y realizados de recaudación de ingresos y gastos públicos en los municipios de las Regiones Inmediatas de Teófilo Otoni y Águas Formosas, estado de Minas Gerais,de los años financieros de 2013 a 2018 y clasificarlos según su efectividad. Los datos recolectados del sitio web del Tribunal de Cuentas del Estado de Minas Gerais (TCE-MG) fueron organizados en hojas de cálculo de Panel Data balanceadas, con un Modelo de Efectos Fijos. Para clasificar las variables dummy se utilizaron los puntajes del I-Planejamento (un índice de planificación presupuestaria) e I-Fiscal (un índice de recaudación de impuestos) que componen el IEGMTCEMG (Índice de Efectividad de la Gestión Municipal porel TCE-MG); y para medir el nivel de inexactitud de los municipios se aplicó la clasificación del programa PEFA. Los resultados mostraron que, según la clasificación PEFA, la mayoría de los municipios pueden ser considerados inexactos, en relación tanto con los ingresos como con los gastos, recibiendo el peor puntaje en el programa, conceptualizado por la letra D. También se encontró que en la estimación econométrica en la variable independiente "Población"y las variables dummy fueron significativas para explicar esta inexactitud.

Palabras clave: Planificación pública; Imprecisión presupuestaria; Ingresos y gastos públicos.

\section{Introdução}

Dentre os instrumentos orçamentários que vêm recebendo cada vez mais atenção no contexto da Gestão Financeira Pública, é possível destacar o planejamento e o orçamento público e, consequentemente, os relatórios de receitas e despesas públicas, publicados em periodicidade anual nos portais de transparência de cada município, pois nestes relatórios, assim como no Plano Plurianual (PPA), a Lei de Diretrizes Orçamentárias (LDO) e com a Lei Orçamentária Anual (LOA) é possível identificar a situação financeira dos municípios e saber com clareza o que foi previsto e o que foi arrecadado, para, posteriormente, mensurar se um município é impreciso, preciso, eficiente ou ineficiente em relação às suas finanças.

A previsão entre receitas e despesas é de grande importância para o desempenho de bons resultados acerca do que foi planejado (Piza, 2016), e para o bom gerenciamento dos recursos públicos. Alves (2015) corrobora com a ideia e descreve que o orçamento é um instrumento do planejamento e que, portanto, deve possibilitar ajustes entre a previsão e a execução, respeitando a transparência fiscal e a legitimidade da LOA.

Neste sentido, a Lei de Responsabilidade Fiscal (LRF) é de grande relevância para o cumprimento das finanças públicas. Nos Artigos 11 e 12 da LRF é notória a exigência para previsão e efetiva arrecadação conforme normas técnicas e uso da legislação para cada ente da Federação. Já nos Artigos 15 e 16 são descritas as exigências para as adequações, compatibilidade e previsão de despesas como proposto no PPA, LDO e LOA (Brasil, 2000).

Corrêa (2004) esclarece que o planejamento está intimamente ligado ao orçamento e que a previsão orçamentária difere dos recursos financeiros disponíveis pelos entes públicos, pois falar em orçamento, é de certa forma, falar em previsão.

Por outro lado, a imprecisão orçamentária pode ser entendida como distanciamento entre as estimativas orçamentárias e sua execução sendo que o seu grau pode estar relacionado com diversos fatores como a falta de capacidade técnica na 
elaboração, a intensidade dos controles externos, tais como poder legislativo e sociedade comum, falta de estrutura de planejamento, ausência de mecanismos eficientes de controle interno e modelos de gestão baseadas no incrementalismo (Azevedo, 2013).

O termo sobre imprecisão orçamentária vem sendo amplamente discutido por diversos autores como Alves (2015), Azevedo (2013), Aquino e Azevedo (2015) Carneiro (2018), Fajardo (2016), Piza (2016) e Zielinski, Hirt e Witt (2017), ainda que através de perspectivas diferentes. Sobre o Índice de Efetividade da Gestão Municipal elaborado pelo Tribunal de Contas do Estado de Minas Gerais em parceria com o Instituto Rui Barbosa, é possível destacar os trabalhos de Alves e Lee (2019), Araujo et al. (2021), Passos e Amorim (2018) e Speeden e Perez (2020).

A pesquisa se justifica por relacionar questões sobre previsibilidade orçamentária de interesse público e social pertinentes ao tema, pois, a imprecisão de receitas e despesas públicas impacta diretamente na eficiência, eficácia e efetividade dos serviços destinados à sociedade. Neste contexto, o presente artigo tem como objetivo verificar a imprecisão orçamentária entre as estimativas e arrecadação de receitas e despesas públicas dos municípios delimitados por esta pesquisa entre os exercícios financeiros de 2013-2018 e classificá-las segundo sua efetividade.

No entanto, conforme exposto sobre a temática deste estudo, tem-se a seguinte questão que norteará esta pesquisa: qual o nível da imprecisão orçamentária das receitas e despesas públicas dos municípios das Regiões Imediatas de Teófilo Otoni e Águas Formosas - MG entre os exercícios financeiros de 2013-2018?

Este trabalho está organizado e dividido em quatro seções, além dos aspectos introdutórios. Na sequência, será apresentado um breve esboço sobre os principais fundamentos teóricos para compor a temática deste trabalho. Nas seções três e quatro, descreve-se os procedimentos metodológicos da pesquisa e, posteriormente, analisam-se os resultados obtidos. Por fim, é apresentada as considerações finais e algumas recomendações para novos estudos.

\section{Metodologia}

O universo desta pesquisa compreende todos os municípios da Região Geográfica Imediata de Teófilo Otoni e Águas Formosas do estado de Minas Gerais no período de 2013 a 2018, conforme atualização do Instituto Brasileiro de Geografia e Estatística (2017), sendo que vinte e sete municípios pertencem à região de Teófilo Otoni e sete municípios são pertencentes à região de Águas Formosas, totalizando trinta e quatro municípios ao longo de 06 anos, totalizando 204 observações. A escolha do período é justificada por conter informações existentes e que podem ser facilmente acessadas, com exceção da classificação do Índice de Efetividade da Gestão Municipal/TCEMG, que passou a ser realizado no estado de Minas Gerais a partir do ano de 2015.

Para Pereira et al., (2018) o método está relacionado com o percurso adotado pelo pesquisador para produzir uma pesquisa, uma vez que se conhece o caminho, ficará mais fácil de realizar e saber onde chegar com a investigação. Neste ponto, foi adotada a metodologia descritiva e quantitativa pela sua natureza de estudo.

Nesta perspectiva, o método descritivo consiste em revelar as particularidades de determinado fenômeno e a relação das variáveis no estudo proposto. Sua principal característica está associada na utilização da padronização em coleta de dados (Gil, 2008). Na metodologia quantitativa, utiliza-se da coleta de dados numéricos "por meio do uso de medições de grandezas e obtém-se por meio da metrologia, números com suas respectivas unidades. O enfoque matemático, muitas vezes, torna-se importante por possibilitar a previsão dos acontecimentos" (Pereira et al., p. 69, 2018). A técnica utilizada neste estudo foi a de dados em painel. Dentro da literatura econométrica, Gujarati e Porter (2011) é considerado um clássico, sendo muito referenciado em pesquisas que faz uso de dados em painel.

Gujarati e Porter (2011) descrevem que esta metodologia é a mais escolhida para a análise de variáveis econômicas, os dados em painel são uma mescla entre cross-section e séries temporais. Baltagi (p. 5-6, 2005), cita algumas vantagens em se 
usar dados em painel, a saber: A) visto que os dados em painel se relacionam a indivíduos, no decorrer do tempo, haverá uma tendência nas unidades analisadas de heterogeneidade. B) na combinação de dados temporais com observações de corte transversal, os dados em painel possibilitam "dados mais informativos, maior variabilidade, menor colinearidade entre variáveis, mais graus de liberdade e mais eficiência". C) os dados em painel são mais apropriados para o entendimento dos processos de mudança. D) utilizando dados em painel será possível "identificar e medir efeitos que simplesmente não são detectáveis em dados de pura secção transversal ou de pura série temporal". E) os dados em painel são os mais indicados para a análise de modelos que apresentam características mais complicadas. F) os dados em painel permitem a minimização de milhares de unidades sobre determinado grupo de indivíduos. Em regra, os dados em painel tornam-se mais eficaz para a pesquisa analisada sobre os dados de séries temporais ou de corte transversal.

Gujarati e Porter (2011) esclarecem que no modelo de efeitos fixos o intercepto pode variar entre os indivíduos, no entanto, podemos dizer que o intercepto relacionado aos indivíduos não são variantes ao longo do tempo; ele se mantém constante no tempo. Em outro ponto, é relevante também destacar o método de efeitos aleatórios (MEA), no qual consiste em transcrever os valores do intercepto de forma aleatória. Gujarati e Porter (2011) faz algumas advertências quanto ao uso de efeitos fixos: como não usar muitas variáveis dummies, pois poderá ocorrer problemas de falta de graus de liberdade e multicolinearidade, ou seja, muitas dummies podem limitar a análise estatística e dificultar a estimação exata dos parâmetros.

Segundo Gujarati (2006), o modelo de efeitos fixos pode ser representado pela seguinte equação 1:

$$
Y_{\mathrm{it}}=\beta_{\mathrm{i}} X_{\mathrm{it}}+\alpha_{\mathrm{i}}+u_{\mathrm{it}}
$$

Em que, $Y_{\text {it }}$ simboliza a variável dependente, $\beta_{\text {it }}$ são os coeficientes a serem estimados, $X_{\text {it }}$ simboliza o conjunto de variáveis explicativas, $\alpha_{\mathrm{i}} \mathrm{são}$ os efeitos não observados e $u_{\mathrm{it}}$ simboliza o termo de erro. O modelo de efeitos aleatórios pode ser caracterizado pela equação 2:

$$
Y_{\text {it }}=\beta_{1 i}+\beta_{2 i} X_{i t}+\beta_{1}+w_{i t}
$$

Logo, é determinado um valor médio para o intercepto $\beta_{1}, w_{i t}=\varepsilon_{i}+u_{i t}$, em que $\varepsilon_{\mathrm{i}}$ é parte integrante do corte transversal dos indivíduos, e $u_{\text {it }}$ é o termo de erro de concordância do modelo de séries temporais, e cortes transversais.

Contudo, para saber qual será o modelo mais indicado de MEA ou MEF vai depender das hipóteses do estudo que foram feitas sobre a provável ligação entre a exatidão do termo de erro ao corte transversal ou individual, aos regressores e, também, da aplicação do teste de Hausman (1978), que segundo Gujarati e Porter (2011) tem uma distribuição assintótica.

Para obter os efeitos acerca da imprecisão orçamentária sob a variável Produto Interno Bruto Per capita, população, Iplanejamento e I-fiscal dos municípios analisados, recorreu-se ao modelo econométrico de dados em painel, criando a seguinte equação 3:

$$
R D T_{i t}=\beta_{O}+\beta_{1} P I B P C_{i t}+\beta_{2} P O P_{i t}+\text { DIPlan }+ \text { DIFisc }+\varepsilon_{i t}
$$

Onde, $R D T_{\text {it }}$ simboliza as variáveis dependentes receitas e despesas totais dos municípios das Regiões Imediatas de Teófilo Otoni e Águas Formosas no período de 2013 a 2018, $\beta_{1}$ e $\beta_{2}$ são os coeficientes a serem estimados; $P I B P C_{\text {it }}$ simboliza Produto Interno Bruto Per capita e POP it população dos municípios e são as variáveis independentes de interesse do modelo, $\operatorname{logo}, \varepsilon_{\text {it }}$ simboliza o termo de erro da equação, sendo este considerado iid (identicamente e independentemente distribuídos 
com $N \sim\left(0, \sigma^{2}\right)$. Foi inserida também, duas dummies (DIPlan e DIFisc) na pesquisa, o I-planejamento e o I-fiscal, conforme notas do Índice de Efetividade da Gestão Municipal/TCEMG.

\subsection{Fonte dos dados utilizados}

Os dados para a análise das variáveis dependentes receitas e despesas dos municípios foram coletados no website do Tribunal de Contas do Estado de Minas Gerais (TCE-MG). Os dados referentes ao ano de 2013 foram repassados por e-mail pelo TCE-MG após solicitação formal por meio da Lei de Acesso à Informação.

Para a análise das variáveis independentes população e PIB per capita, foram obtidos no website do Instituto Brasileiro de Geografia e Estatística (IBGE).

Por sua vez, o Índice de Efetividade da Gestão Municipal (IEGM) orientou a composição das variáveis qualitativas (Dummies) I-planejamento e I-fiscal foram obtidos no website do Instituto Rui Barbosa (IRB).

\subsection{Caracterização das variáveis}

A variável dependente é simbolizada pela letra $\left(Y_{\text {itt }}\right)$ e está relacionada com os valores e eventos a serem explicados pelo pesquisador sobre o fenômeno estudado e que são influenciados pela variável independente. Em outro aspecto, a variável independente é normalmente definida pela letra $\left(X_{\text {it }}\right)$ e faz alusão ao fator determinante, e as possíveis causas ou condições para chegar em determinado resultado, ou seja, essa variável é utilizada pelo pesquisador para saber as causas do resultado de Y influenciado por X (Marconi \& Lakatos, 2003).

Nesta perspectiva, tem-se como variáveis dependentes as receitas e despesas públicas, conceituadas anteriormente neste trabalho. E como variáveis independentes foram adotados o Produto Interno Bruto Per capita e a população dos municípios analisados. Para Melo e Morandi (2021), o PIB per capita é um indicador econômico utilizado para auxiliar a identificar a realidade socioeconômica de um país, estado ou município, dividindo a soma dos bens e serviços por cada indivíduo dentro de sua respectiva população.

Gujarati e Porter (2011) lembram sobre a importância de incluir variáveis binárias (dummies) na pesquisa, pois elas explicam os fenômenos de origem qualitativa e podem ser usadas com a mesma facilidade de variáveis quantitativas. Estas variáveis assumem valores de 0 ou 1 e são utilizadas para classificar dados em categorias mutuamente exclusivas, como exemplo: se determinado planejamento é efetivo (1) ou se não é efetivo (0).

Nesta perspectiva, pretendeu-se captar o efeito das dummiesI-planejamento e I-fiscal sobre a imprecisão orçamentária. No entanto, não foi possível essa captação nos anos de 2013 e 2014 nos 34 municípios, visto que o Índice de Efetividade da Gestão Municipal era inexistente neste período, em Minas Gerais, assim, todos os municípios assumem valor 0 nos anos mencionados. Nos demais anos, esta variável assume valor 1 em função da existência do Índice de Efetividade da Gestão Municipal.

O Índice de Efetividade da Gestão Municipal/TCEMG é realizado anualmente, com respaldo na Resolução nº 06/2016 e Instrução Normativa n $n^{\circ}$ 01/2016 e promove avaliações sob sete dimensões da gestão pública quanto à execução do orçamento público: Educação; Saúde; Planejamento; Gestão Fiscal; Meio Ambiente; Cidades Protegidas; Governança em Tecnologia da Informação. O IEGM visa o entendimento de como o planejamento público é elaborado e executado de fato sob os critérios da eficiência e eficácia (Manual IEGM, 2019).

O Índice Municipal do Planejamento (i-Planejamento/TCEMG) "verifica a consistência entre o que foi planejado e o efetivamente executado, por meio da análise dos percentuais gerados pelo confronto destas duas variáveis". Em outro ponto o Índice Municipal da Gestão Fiscal (i-Fiscal/TCEMG) "mede por meio da análise da execução financeira e orçamentária, das 
decisões em relação à aplicação de recursos vinculados, da transparência da administração municipal e da obediência aos limites estabelecidos pela Lei de Responsabilidade Fiscal" (Anuário, p. 10, 2015).

Os resultados que classificam os municípios são apresentados pelas seguintes notas: A (altamente efetiva); B+ (muito efetiva); B (efetiva); C+ (em fase de adequação); C (baixo nível de adequação) (Manual IEGM, 2019).

Em outra perspectiva, para identificar o nível de imprecisão orçamentária dos 34 municípios, é imprescindível a utilização dos instrumentos do orçamento público, como relatórios de receitas e despesas, assim como o Plano Plurianual (PPA), a Lei de Diretrizes Orçamentárias (LDO) e a Lei Orçamentária Anual (LOA). Com esses documentos é possível identificar a situação financeira dos municípios e aplicando a metodologia do PEFA framework pode-se obter o nível de imprecisão orçamentária destes municípios.

A Gestão das Finanças Públicas ou PFM (Performance Financial Management) em diversos países tem sido avaliada por órgãos de cooperação internacional, como por exemplo, o Banco Mundial e o Fundo Monetário Internacional (FMI). As avaliações e comparações podem ser realizadas através de índices e medidas utilizando os parâmetros definidos pelo PEFA (Public Expenditure and Financial Accountability/Programa de Despesas Públicas e Responsabilidade Financeira)que para chegar ao objetivo da GFP faz uso de sete pilares do ciclo orçamentário, entre eles: transparência das finanças públicas, gestão de ativos e passivos, estratégia fiscal e orçamentação baseadas em políticas, contabilidade e relatórios, escrutínio e auditoria externa, previsibilidade e controle na execução do orçamento e por fim, credibilidade do orçamento, sendo este utilizado nesta pesquisa.

A metodologia do PEFA framework já foi utilizada para avaliar o desempenho financeiro em mais de 149 países e o programa classifica a imprecisão quanto às receitas e despesas de maneira separada. Segundo o PEFA framework, a imprecisão do orçamento para receitas é baixa quando estas ficam entre $97 \%$ e $106 \%$ dos valores previstos inicialmente para a arrecadação. No que tange às despesas, a imprecisão é considerada baixa quando estas não ultrapassam $95 \%$ e $105 \%$ do valor previsto inicialmente (PEFA, 2019).

\section{Referencial Teórico}

\subsection{Planejamento e Orçamento Público}

A partir da Constituição de 1988, os processos para o planejamento e orçamento no Brasil foram estruturados de maneira inovadora introduzindo os modelos atualmente utilizados como o Plano Plurianual (PPA), a Lei de Diretrizes Orçamentárias (LDO) e a Lei Orçamentária Anual (LOA) para serem executados em todas as esferas de governo.

A partir desta exigência na forma da lei para a elaboração dos Orçamentos dos entes públicos no Brasil, o referido instrumento de gestão passou por diversas transformações até ser considerado uma ferramenta com função que ultrapassa a linha da sua origem administrativa que transmitia a ideia de algo estritamente técnico que não recebia influência externa na sua construção.

Contudo, Oliveira e Ferreira (2017) alertam que o orçamento e o ciclo orçamentário estarem inseridos na Constituição Federal não garante a unidade na interpretação da sua natureza jurídica e da sua materialidade. Baldo (2018) aponta o orçamento como um instrumento do planejamento dotado de poder político e democrático que deve atender a economicidade gerencial e a participação da sociedade.

Aquino e Azevedo (2015) corroboram Baldo (2018), exemplificando que a destinação dos recursos dentro da sociedade de forma direcionada é um reflexo do poder social e político do orçamento. Os autores acrescentam também que o orçamento está em constante mudança e que a discussões realizadas em torno deste instrumento são oriundas de diferentes vertentes.

Neste ponto, Motta (2004) descreve que o planejamento pode ser visto como um método de aprendizado para 
determinado fim, como exemplo: buscar entendimento e saber quais são as demandas e necessidades externas da sociedade para que a administração local possa trazer soluções. Nesta perspectiva, ele ressalta:

O exercício estratégico procura reconhecer mudanças atuais e potenciais na comunidade e na própria administração e reinterpretar como essas mudanças afetam o atual sentido de direção. Criação e renovação das formas de perceber o trabalho facilitam o desenvolvimento de novas referências e, portanto, de ações mais harmoniosas, independentemente de reuniões periódicas para a resposta a problemas (Motta, 2004, p. 51).

No entanto, Costa e Cunha (2004, p. 75) descrevem que o planejamento estratégico é um grande aliado para o desenvolvimento municipal e que este deve ocorrer de forma "contínua, sistemática e permanente, deve ser participativo e ascendente, regionalizado, descentralizado e integrado". Os autores ainda complementam que para ocorrer o sucesso das ações públicas a participação dos grupos da sociedade civil organizada no processo de planejamento é de grande relevância e que, desta forma, será mais fácil de atingir os objetivos da localidade e, consequentemente, resultará no melhor aproveitamento dos recursos disponíveis.

\subsection{Orçamento Programa e a Formulação de Políticas Públicas}

Dentre as vertentes possíveis de serem apresentadas como técnica para elaboração de orçamento público, é possível exemplificar o orçamento participativo, o orçamento base-zero, o orçamento de desempenho, o tradicional e o orçamentoprograma, sendo este o modelo atribuído para a execução das diversas políticas públicas nas três esferas da Administração Pública no Brasil.

Não obstante, destaca-se nesta pesquisa o uso do orçamento-programa, o qual Santos et al. (2017) expõe que não há unanimidade entre autores sobre o momento histórico atribuído ao uso do orçamento-programa no Brasil. Citando, por exemplo, a discordância entre autores que sugerem a utilização desta técnica orçamentária desde a Lei $n^{\circ} 4.320 / 64$ ou que atribuem a adoção da referida técnica a partir da década de 2000, quando foram criadas leis que regulamentaram a atividade orçamentária como a Lei Complementar n 101/2000, também conhecida como Lei de Responsabilidade Fiscal.

Santos et al. (2017) mencionam que o orçamento-programa é avaliado por indicadores de desempenho, reforçando o entendimento de Giacomoni (2010) quando este sugere que orçamento de desempenho e o orçamento-programa não devem ser dissociados.

Segundo os autores, o orçamento-programa é importante na implantação e execução de políticas públicas:

(...) o orçamento por programas representou um importante passo no aprimoramento da programação das despesas, pois passou a ser um instrumento de operacionalização das ações do governo, em conformidade com os planos e diretrizes formulados no planejamento estratégico (Santos et al., 2017, p. 209).

Azevedo e Aquino (2016) apontam que na evolução orçamentária brasileira, a implantação do orçamento-programa ocorreu a partir do ano de 2002, sendo posterior à solidificação do ciclo orçamentário e das exigências estabelecidas pela Lei de Responsabilidade Fiscal.

Em outro ponto, Boneti (2018) menciona que para elaboração das políticas públicas é necessário a participação de inúmeros agentes, como a sociedade civil, os movimentos sociais e o poder Legislativo. $\mathrm{O}$ autor ainda destaca a participação dos agentes do poder que interferem nas políticas públicas por possuírem relações de amizades com pessoas de grande influência, capital, experiência legal e política. Vale ainda ressaltar a participação dos burocratas na elaboração das políticas públicas, estes são profissionais especializados no tema e tendem a favorecer os interesses de alguma classe social.

Valle (2018) alerta que, por vezes, os planejamentos definidos na estrutura orçamentária através de seus programas 
podem ser dissociados das políticas públicas por fatores diversos como, por exemplo, competição por influência política, o desinteresse dos agentes públicos no comprometimento de ações detalhadas através de planejamento.

Ao analisar os gastos públicos municipais com ideologia partidária, Rodrigues (2010) conclui que, de maneira geral, os municípios não sofrem alterações nos investimentos orçamentários em políticas públicas locais quando se altera o viés ideológico de esquerda, centro ou direita e que as variações dos gastos públicos são cíclicas.

Cunha e Rezende (2005) coloca em pauta a discussão do caráter incrementalista do orçamento na administração pública brasileira e ressalta a importância de reduzir o caráter incrementalista para que a gestão tenha um padrão de qualidade mais alinhado com o planejamento elaborado inicialmente pelas propostas orçamentárias enviadas ao poder legislativo.

\subsection{Transparência Pública}

Vincular o planejamento ao orçamento é uma demonstração de mudança de pensamento dos agentes da Administração Pública, assim como uma oportunidade de conscientização do cidadão com relação ao uso dos recursos públicos.

Dias et al. (2020) cita a Lei de Responsabilidade Fiscal (LRF) do ano 2000 como o marco regulatório da transparência no Brasil, sendo este o dispositivo legal que rege sobre a obrigatoriedade de divulgação de dados fiscais, orçamentários e outros indicadores através de portais eletrônicos. Os autores acrescentam ainda que, posteriormente, a LRF foi ampliada com mais duas leis, sendo: A Lei de Transparência e a Lei de Acesso à Informação, elaboradas no ano de 2009 e 2011, respectivamente.

Cruz, Silva e Spinelli (2016) enaltecem a LRF e discorre que ela é que garante a transparência no cumprimento dos processos de elaboração do ciclo orçamentário na forma da lei permitindo a participação da sociedade na construção do PPA, da LDO e LOA assim como posterior acesso aos relatórios de gestão financeira que demonstram os resultados da execução orçamentária.

A LRF estabelece, além do cumprimento dos institutos do ciclo orçamentário, a definição quanto aos limites de despesas com quadro de pessoal, o endividamento entre outros pontos que restringem as despesas orçamentárias em equilíbrio com as receitas (Speeden \& Perez, 2020).

Cruz, Silva e Spinelli (2016) mencionam que a alteração da Lei de Responsabilidade Fiscal pela Lei de Transparência no ano de 2009 possibilitou o amplo acesso às receitas e despesas dos entes da Administração Pública por qualquer cidadão ou empresa através da disponibilização de dados abertos nos portais de transparência com o maior detalhamento possível.

Belline et al. (2017) destaca que a Lei de Acesso à Informação de 2011 consolida o acesso à informação pública, estabelece sobre os procedimentos da Administração Pública quanto ao retorno das informações públicas solicitadas pelos cidadãos.

A Lei carrega como um dos princípios a ideia de que o sigilo é a exceção tal como é expresso:

Um dos princípios da Lei é que a publicidade e a transparência das informações é a regra, e o sigilo, a exceção, sendo restringido o acesso apenas em situações específicas, como nos casos em que a divulgação das informações coloque em risco a segurança da população, do estado, ou a defesa do território nacional. Ela é de cumprimento obrigatório para todos os entes, de todas as esferas governamentais, produzindo grandes impactos na gestão pública, exigindo para sua efetiva implementação a adoção de uma série de medidas que podem ser auxiliadas pela CGU (Belline et al., 2017, p. 92).

Com relação aos municípios, a LAI prevê que municípios acima de 10 mil habitantes devem disponibilizar em seu endereço eletrônico de internet informações como registro de competências, estrutura organizacional, registros orçamentários diversos, processos licitatórios entre outras no denominado portal da transparência (Cruz; Silva \& Spinelli, 2016). 
Baldissera et al. (2020) comenta em seus estudos a relação existente entre a boa governança e as práticas de transparência assim como Speeden e Perez (2020), coloca as práticas de transparência como um requisito essencial para uma boa governança. Uma boa governança através de uma gestão transparente reduz o risco de moral negativa, facilita o acompanhamento da sociedade e diminui as ações de caráter ilícito (Baldissera et al., 2020).

\subsection{Avaliação Sob a Ótica Da Eficiência, Eficácia e Efetividade}

A administração pública deve pautar suas atividades através de processos que visam eficiência, eficácia e efetividade nos seus resultados. Para Carneiro (2018), estes indicadores são pilares da boa governança e são aliadas da responsabilidade e da transparência.

Pinto e Coronel (2017) discutem os termos eficiência e eficácia afirmando que ambos muitas vezes são classificados como sinônimos, porém são diferentes nas suas concepções, apesar de serem indicadores de desempenho das organizações. Os autores esclarecem que a eficiência está relacionada com os meios e a eficácia com os resultados. Assim, uma organização pode ser eficiente e eficaz ou possuir apenas um destes atributos no desempenho de suas atividades.

No âmbito da Administração Pública, Paludo (2013) difere o conceito de eficácia e efetividade, pois apesar dos dois indicadores estarem relacionados com os resultados, o primeiro abrange o atingimento de metas e o segundo atinge o alcance social e o impacto final das ações executadas.

Bairral, Silva e Alves (2015) discutem a relação da transparência e o envolvimento da sociedade na administração pública indicando que quanto maior a participação dos cidadãos, maior o foco da gestão na busca pela eficiência, eficácia e efetividade.

Carneiro (2018, p. 20) destaca a Emenda Constitucional $n^{\circ} 19 / 98$ que incluiu o princípio da eficiência na administração pública exigindo-se assim que as suas atividades sejam realizadas com "presteza, perfeição e rendimento funcional".

Neste sentido, destaca-se a importância do planejamento e do controle gerencial para a alocação de recursos com indicadores de eficácia e eficiência. Carneiro (2018) complementa que os indicadores são importantes para o orçamento público e que após a inclusão da eficiência como princípio da administração pública na Constituição Federal, os indicadores abordados neste tópico passaram a ter maior validade jurídica.

Paludo (2013) inclui a economicidade como um indicador de desempenho para avaliação da gestão pública pelos mecanismos de controle sendo este conceituado como o processo de redução de custos das atividades desempenhadas sem comprometimento da qualidade no resultado final.

Por fim, é possível compreender que as organizações, incluindo o setor público, podem ter desempenho nos processos e resultados com atributos de economicidade, eficiência, eficácia e efetividade. Contudo, é absolutamente possível que um órgão possua estes atributos de maneira parcial.

\subsection{Receitas Orçamentárias}

Para definir receita pública, Fiirst et al. (2017) se alicerçam do conceito proposto pela Secretaria de Orçamento Federal (SOF), a qual traz e ensina que receitas públicas são os recursos financeiros disponíveis pelos governos para atender as necessidades coletivas da sociedade através dos programas de governo.

Segundo os autores, a SOF elaborou uma metodologia para a elaboração da previsão das receitas orçamentárias utilizando de critérios técnicos para tornar a gestão pública mais eficiente para garantir os direitos delineados pela Constituição Federal. 
Neste trabalho, é importante salientar que o termo "receita orçamentária" pode ser substituído ocasionalmente por "receita pública", assim como adotado pela SOF.

As receitas são categorizadas conforme sua categoria econômica origem conforme tabela elaborada pela Secretaria de Orçamento Federal a seguir:

Tabela 1: Classificação das receitas orçamentárias.

\begin{tabular}{ll}
\hline \multicolumn{1}{c}{ CategoriaEconômica $\left(1^{\circ}\right.$ Dígito $)$} & \multicolumn{1}{c}{ Origem ( $2^{\circ}$ Dígito) } \\
\hline 1 - Receitas Correntes & 1 - Impostos, Taxas e Contribuições de Melhoria \\
7 - Receitas Correntes Intraorçamentárias & 2 - Contribuições \\
& 3 - Receita Patrimonial \\
& 4 - Receita Agropecuária \\
& 5 - Receita Industrial \\
& 6 - Receitas de Serviços \\
& 7 - Transferências Correntes \\
& 9 - Outras Receitas Correntes \\
\hline 2 - Receitas de Capital & 1 - Operações de Crédito \\
- Receitas de Capital Intraorçamentárias & - Alienação de Bens \\
& 3 - Amortização de Empréstimos \\
& 4 - Transferências de Capital \\
& 9 - Outras Receitas de Capital \\
\hline
\end{tabular}

Fonte: Manual Técnico Orçamentário (2022).

Com relação aos municípios, Azevedo (2013) apresenta que, aproximadamente, 94\% dos municípios brasileiros possuem cerca de $70 \%$ de suas receitas originadas de transferências intergovernamentais, o que prova a dependência dos municípios na captação de recursos para execução das políticas públicas.

Fiirst et al. (2017) ensinam que, periodicamente, o orçamento deve ser ajustado para verificar se o valor de arrecadação corresponde às previsões iniciais para que os recursos sejam realocados conforme necessidade para garantir que a Lei de Responsabilidade Fiscal seja cumprida.

Contudo, os autores discordam do disposto no Art. 12 da Lei Complementar nº 101/2000, a Lei de Responsabilidade Fiscal, que em seu texto determina o período de referência dos últimos três anos para projeções orçamentárias, argumentando que este período seja insuficiente ao considerar eventos e sazonalidades.

\subsection{Despesas Orçamentárias}

Com referência às despesas orçamentárias, neste trabalho rege o mesmo conceito de despesa pública qual Vieira (L) se alicerça em Kahoma (2014) para definir que estas são os gastos fixados através das Leis do ciclo orçamentário que direcionam a execução dos serviços públicos ou para a aquisição de patrimônio.

O Manual Técnico Orçamentário (2022) recomenda a classificação das despesas em correntes e de capital, assim como é definido para o trato com as receitas públicas.

Vieira (2016) cita Paludo e Procopiuck (2014) para demonstrar que as despesas públicas devem ser organizadas observando as despesas de Pessoal, as contratuais e obrigatórias, projetos de grande impacto e novos investimentos, necessidades no setor de informática, capacitação e treinamento, despesas com passagens e diárias, manutenção geral e outras de caráter específico.

Marques Junior (2018) alerta que as despesas, assim como as receitas, podem sofrer alterações no decorrer da execução orçamentária por motivos diversos tais como mudanças no ambiente econômico ou eventos extraordinários como calamidades públicas.

Nesta perspectiva, Baldo (2018) frisa que as despesas orçamentárias devem ser fixadas e orientadas pelas leis do ciclo 
orçamentário observando sua continuidade conforme os programas direcionados no Plano Plurianual, na Lei de Diretrizes Orçamentárias e na Lei Orçamentária Anual.

Neste sentido, Carneiro (2018) salienta que as despesas orçamentárias não podem ser autorizadas por lei sem a existência de recursos para que estas sejam financiadas. Assim, o orçamento público permite que periodicamente as leis que regem o orçamento sejam revisadas e reformuladas caso seja necessário.

\section{Resultados}

\subsection{Porte dos Municípios}

A pesquisa adotou a classificação de porte de municípios em conformidade com sua população considerando o IEGM-TCEMG. Sendo assim, considera-se os municípios com população inferior ou igual a 5.000 habitantes como "muito pequeno", aqueles com população maior que 5.000 e menor ou igual a 20.000 habitantes como "pequeno", aqueles com população maior que 20.000 e menor ou igual a 200.000 habitantes como "médio" e acima de 200.000 habitantes como "grande".

Os 34 municípios investigados foram identificados quanto ao porte para cada ano definido no espaço temporal desta pesquisa, sendo as informações populacionais extraídas das estimativas divulgadas pelo IBGE.

Figura 1: Classificação dos municípios conforme porte populacional.

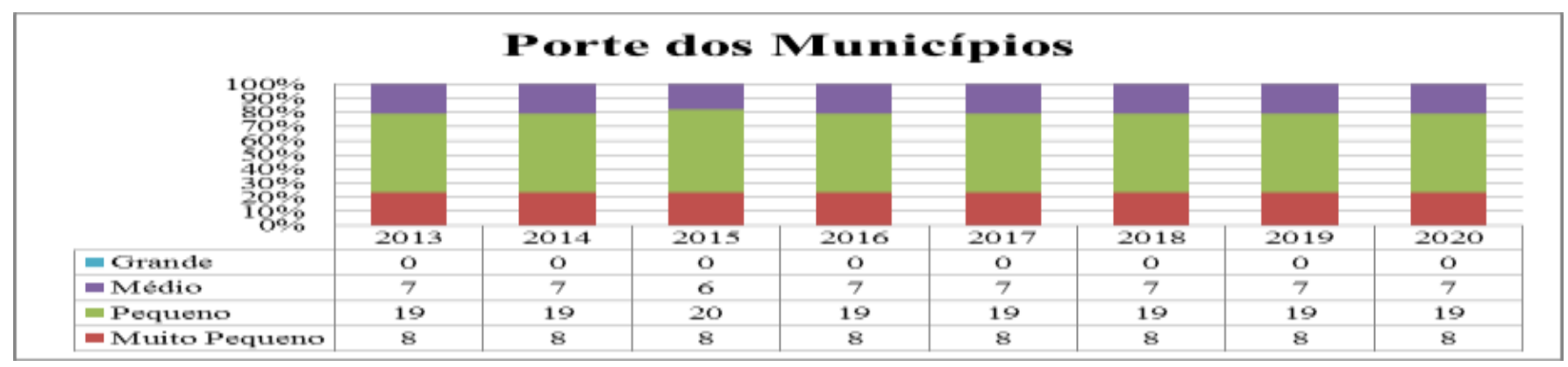

Fonte: Elaboração com base nos dados do IBGE (2021).

Os resultados, conforme Figura 1, não apresentam variações significativas no porte dos municípios no período de 2013 a 2018, sendo possível observar a migração de um município considerado de "médio" nos anos 2013 e 2014 para "pequeno" no ano de 2015 e logo se enquadrando para "médio", novamente, a partir do ano de 2016. Neste caso, trata-se especificamente do município de Carlos Chagas.

O levantamento realizado, mesmo considerando a exceção observada no parágrafo anterior, permitiu observar que a região que compõe as zonas imediatas de Teófilo Otoni e Águas Formosas é formada, em sua maioria, por municípios de pequeno porte, representando, aproximadamente, $56 \%$ do total de municípios. O restante da região é composta por municípios considerados "médios" ou "muito pequenos", sendo representados na ordem de $20 \%$ e $24 \%$, respectivamente.

Speeden e Perez (2020) consideram que o porte dos municípios é uma variável de grande importância para se mensurar a qualidade do planejamento orçamentário. Neste caso, para uma estimativa menos imprecisa é necessário dividirmos municípios pelo seu número de população e classificá-los como muito pequeno, pequeno, médio e de grande porte.

\subsection{I-Planejamento}

Com relação ao I-Planejamento, os dados captados do IEGM-TCEMG para o período de 2015 a 2018 revelaram que a maior parte dos municípios recebeu nota B (Efetiva) ou nota $\mathrm{C}+($ Em fase de adequação), totalizando um resultado maior que $70 \%$ do total de municípios observados (FIGURA 2). 
Figura 2: Classificação dos municípios segundo o I-Planejamento.

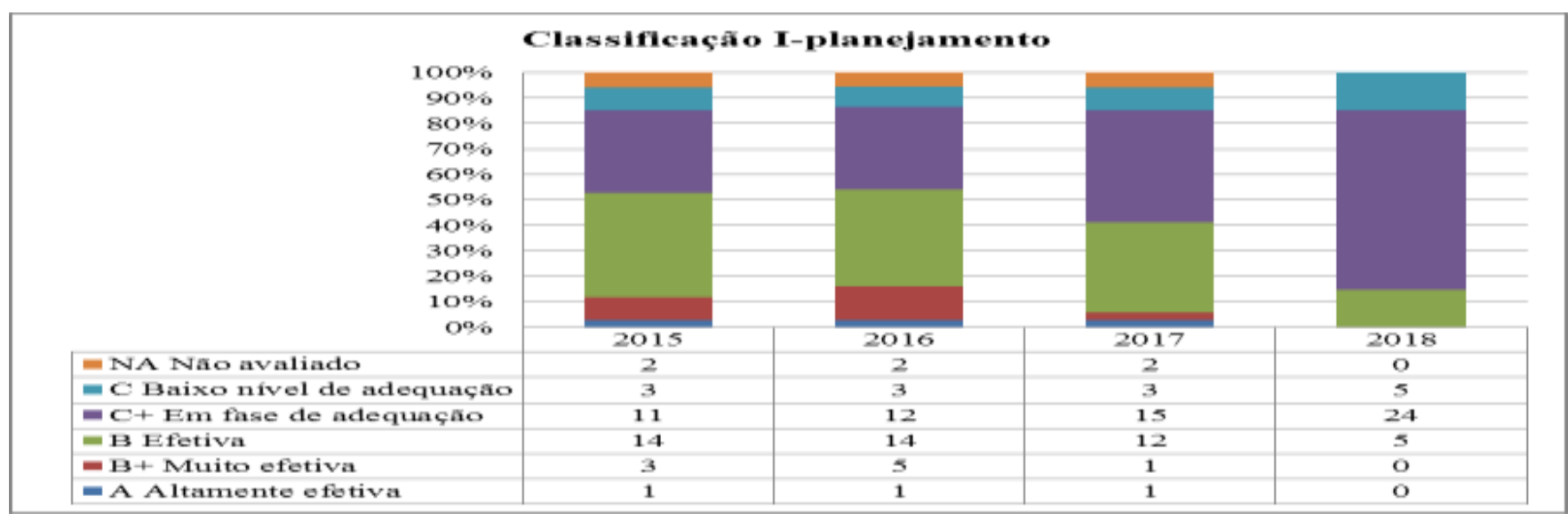

Fonte: Elaboração com base nos dados do IEGM-MG (2021).

Foi possível notar, pela Figura 2, uma redução no conceito da efetividade do I-Planejamento dos 34 municípios observados ao comparar os resultados dos anos iniciais até o último ano apontado, visto que, em 2018, não houve municípios com conceito A ou B nos resultados do I-Planejamento, conforme pode ser observado na Figura 2 apresentada.

Existe uma relação entre o porte dos municípios e as notas do I-planejamento em que à medida que os grupos de municípios maiores são avaliados as notas são cada vez menores, refutando a ideia de que os municípios maiores com um corpo técnico provavelmente mais capacitado possuem instrumentos de planejamento e orçamento mais qualificados (Speeden \& Perez, 2020).

Contudo, é preciso observações de outras variáveis para compreender as causas dos resultados apresentados e as relações que estas possuem com outras variáveis como, por exemplo, a imprecisão orçamentária, pois as variações das notas do I-Planejamento não compreendem a ideia apresentada por Speeden e Perez (2020) quando se observa o porte dos municípios observados.

\subsection{I-Fiscal}

Em outro ponto, os dados captados do I-Fiscal para o período de 2015 a 2018 revelaram que a maior parte dos municípios recebeu nota $\mathrm{C}$ (Baixo nível de adequação) ou nota $\mathrm{C}+($ Em fase de adequação), somando um percentual de quase $80 \%$ do total dos municípios observados. É relevante ressaltar que não houve cidades com notas A (Altamente efetiva) ou notas B+ (Muito efetiva) em nenhum dos anos mencionados. 
Figura 1: Classificação dos municípios segundo I-Fiscal.

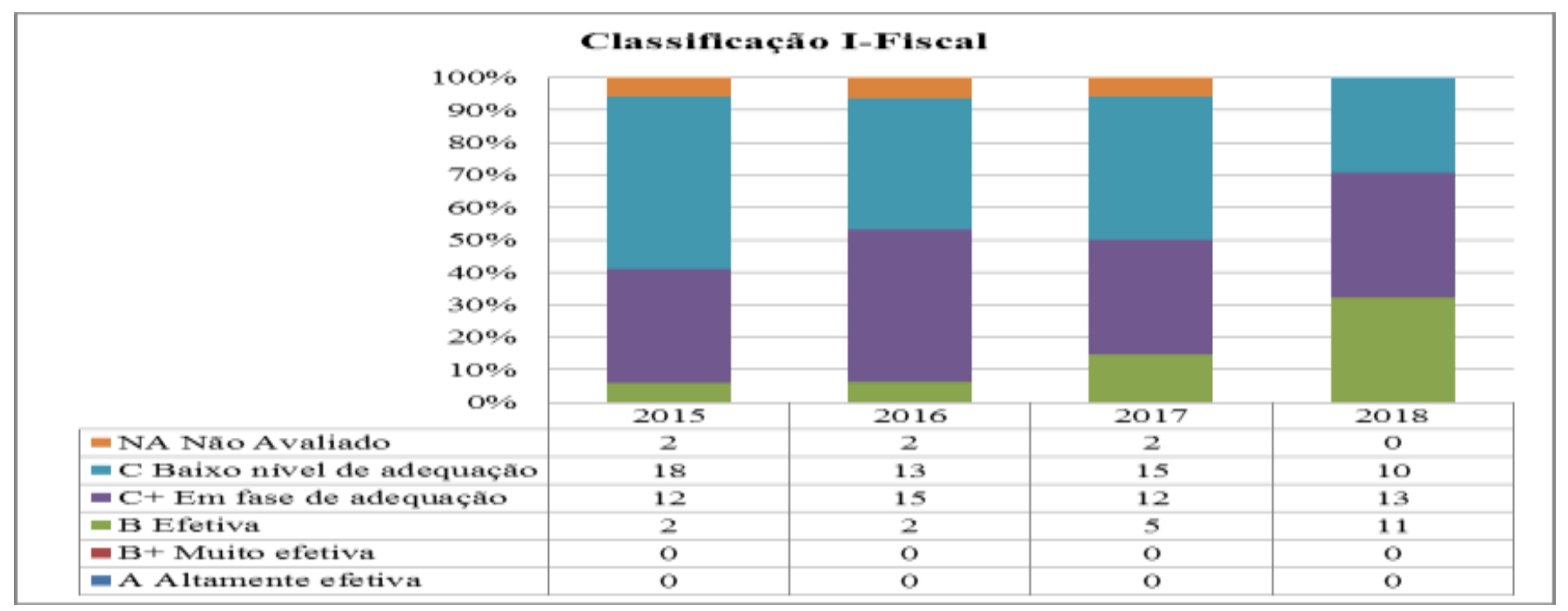

Fonte: Elaboração com base nos dados do IEGM-MG (2021).

Foi possível perceber um crescimento significativo relacionado ao Índice Fiscal dos municípios observados ao longo de todos os anos, visto que 2018 foi o ano de maior evolução neste I-Fiscal, conforme pode ser observado na Figura 3. A evolução no âmbito do Índice Fiscal pode estar relacionada com a obrigatoriedade dos municípios quanto ao cumprimento estabelecido pela Lei de Responsabilidade Fiscal (Alves \& Lee, 2019), sendo que um dos requisitos deste índice está relacionado com a transparência da Administração Municipal e do cumprimento dos limites estabelecidos pela LRF.

\subsection{Nível da Imprecisão Orçamentária dos Municípios}

A partir da captação de dados de receitas e despesas previstas e realizadas para o período observado nesta pesquisa, foi possível configurar, sem considerar outras variáveis, a imprecisão orçamentária dos municípios individualmente para cada ano.

Com efeito, foi possível representar graficamente o grau de imprecisão dos municípios com base nos parâmetros do Programa de Despesas Públicas e Responsabilidade Financeira (PEFA). Para maiores detalhes acerca da análise do programa PEFA aplicada em municípios brasileiros veja Azevedo (2013), Aquino e Azevedo (2015), Zielinski, Hirt e Witt (2017) e Carneiro (2018) a nível estadual. É possível recomendar Teixeira et al. (2021) sobre a metodologia e a importância na aplicação do PEFA Framework.

Os resultados apontam que a maior parte dos municípios tende a ser mais imprecisos com relação às receitas do que para as despesas, mesmo observando que para as duas variáveis a maior parte dos municípios recebeu conceito D em todos os anos. 
Figura 2: Imprecisão orçamentária- receitas e despesas.
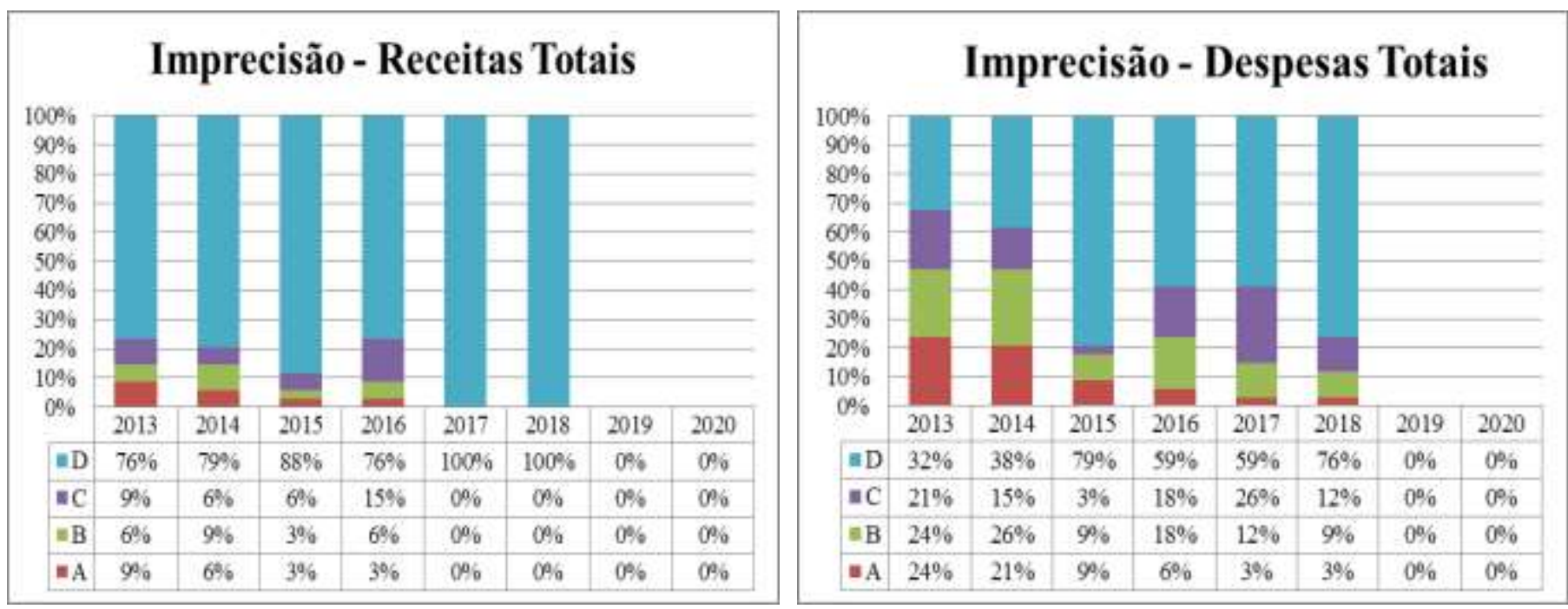

Fonte: Elaboração com base nos dados do TCE-MG (2021)

A pesquisa revelou que, ao considerar as receitas e despesas totais previstas e realizadas, os municípios investigados em sua maioria receberam classificação "D" aplicando o método do PEFA, sendo possível perceber que a imprecisão para as receitas foi maior que para as despesas (Figura 4). Este resultado também foi obtido por Aquino e Azevedo (2015) ao observar o grau de irrealismo orçamentário dos municípios brasileiros.

Neste caso, os resultados apresentados significam que a maior parte dos municípios arrecadam acima de $116 \%$ ou abaixo de $92 \%$ do valor previsto inicialmente no orçamento anual. Da mesma forma, no caso das despesas, os municípios empenham suas despesas acima de $115 \%$ ou abaixo de $85 \%$ dos valores previstos, inicialmente, pelo orçamento anual.

É importante ressaltar nos resultados que podem existir fatores diversos que influenciam o desempenho da acurácia orçamentária de um município. No entanto, variáveis como o porte do município não são determinantes fundamentais que influenciam o nível da imprecisão orçamentária com relação às receitas totais (Fiirst et al, 2017) e para as despesas totais.

Aquino e Azevedo (2015) colocam em discussão as técnicas adotadas pelos municípios nas estimativas orçamentárias que podem ser superestimadas ou subestimadas por critério meramente político. Os autores acrescentam ainda que o grau de informação preliminar pode auxiliar na busca pelo realismo orçamentário. Contudo, ensinam que a prefeitura pode prever quanto à arrecadação de IPTU e ISS teriam maiores possibilidades de realismo na previsão, mas que as arrecadações como o ICMS, por exemplo, nem sempre tem suas previsões divulgadas pelos estados de maneira clara para cada município, o que contribui para o distanciamento do realismo na previsão.

Considera-se também que outros autores também analisaram outros municípios brasileiros com resultados diferentes por motivos que podem estar relacionados com a implementação da Lei de Responsabilidade Fiscal, o que sugere que os anos posteriores à promulgação da referida lei, os municípios tendem a ser mais eficientes nas suas estimativas orçamentárias. Contudo, o gráfico apresenta sinais que incompatibilizam esta hipótese, uma vez que o nível de imprecisão orçamentária permanece fora dos parâmetros que possam sugerir eficiência.

\subsection{Resultados Econométricos}

Como o propósito da estimação dos efeitos acerca da imprecisão orçamentária sob a variável Produto Interno Bruto Per capita, população, I-planejamento e I-fiscal dos municípios analisados, recorreu-se ao modelo econométrico de dados em painel incluindo 34 cidades e um total de 930 observações no período de 2013 a 2018. 
Na Tabela 2, constata-se a análise descritiva das variáveis aplicadas no modelo.

Tabela 2: Estatística descritiva das variáveis no período de 2013 a 2018.

\begin{tabular}{ccccc}
\hline Variáveis & Pib per capita & População & Receitas & Despesas \\
\hline Média & $10.305,94$ & 16.217 & $36.428 .452,57$ & $37.503 .255,65$ \\
& & & & $365.935 .188,33$ \\
\hline Máximo & $20.408,09$ & 141.934 & $11.990 .034,97$ & $11.582 .894,63$ \\
\hline Mínimo & $6.249,19$ & 2.626 & $53.708 .251,76$ & $55.462 .538,34$ \\
\hline D. padrão & $3.257,92$ & 23.436 & & \\
\hline
\end{tabular}

Fonte: Elaborado pelos autores.

Conforme demonstrado na Tabela 2, para a população a média é de 16.217 habitantes na amostra, o máximo é 141.934 e o mínimo é de 2.626. Nas receitas a média é de $\mathrm{R} \$ 36.428 .452,57$ o máximo de $\mathrm{R} \$ 350.920 .119,40$ e mínimo de $\mathrm{R} \$$ 11.990.034,97. E por fim, as despesas representam uma média de $\mathrm{R} \$ 37.503 .355,65$, o máximo é de $\mathrm{R} \$ 365.935 .188,33$ e o mínimo é considerado de $\mathrm{R} \$ 11.582 .894,63$. Tanto para as receitas, quanto para as despesas os valores apresentados são semelhantes com relação ao mínimo, máximo e a média, existindo certa homogeneidade. No entanto, existe uma cidade (Teófilo Otoni) que foge às regras dos demais municípios, pois sua população é muito maior que a maioria dos municípios chegando a um total de 141.934 habitantes, sendo que a menor cidade (Umburatiba) corresponde a 2.626 habitantes e as demais cidades não ultrapassam os 41.800 habitantes.

Deste modo, todas as variáveis, com exceção ao PIB per capita, apresentam discrepâncias quanto aos valores apresentados nesta tabela se comparados a estas duas cidades. Quanto ao PIB per capita, a média na amostra é de R\$ 10.305,94, o máximo foi de $\mathrm{R} \$ 20.408,09$ e o mínimo é equivalente a $\mathrm{R} \$ 6.249,19$, as cidades da amostra são homogêneas quanto a sua riqueza per capita, sendo que o desvio padrão alcança baixo valor $(3.257,92)$, visto que, não há uma discrepância entre os valores do PIB per capita nas cidades se analisarmos o mínimo, a média e o máximo por número de habitantes das cidades.

Fiirst et al. (2017) ensinam que, periodicamente, o orçamento deve ser ajustado para verificar se o valor de arrecadação corresponde às previsões iniciais para que os recursos sejam realocados conforme necessidade para garantir que a Lei de Responsabilidade Fiscal seja cumprida.

Em outro ponto, Baldo (2018) esclarece que as despesas orçamentárias devem ser fixadas e orientadas pelas leis do ciclo orçamentário observando sua continuidade conforme os programas direcionados no Plano Plurianual, na Lei de Diretrizes Orçamentárias e na Lei Orçamentária Anual.

Em outra perspectiva, para apresentar a estimação da equação 3, foram testados os dois modelos de MEF e MEA e realizadas as comparações com o teste de especificação de Hausman (1978), que permite verificar qual o tipo de efeito mais consistente, sendo que a hipótese nula assume a consistência dos estimadores de efeitos aleatórios. Greene (2002) apresenta o teste de Hausman, com as seguintes hipóteses: $\left(H_{0}\right)$ os efeitos individuais não possuem correlação com as variáveis independentes; $\left(H_{l}\right)$ os efeitos individuais possuem correlação com as variáveis explicativas.

No caso de hipótese nula, ou seja, ausência de correlação entre efeitos individuais e regressores, ambos os estimadores de efeito fixo e variável são considerados consistentes, sendo o de efeito aleatório relativamente mais eficiente. Considerando 
que o resultado do teste de Hauman (1978), deve-se aceitar a hipótese nula do teste $\left(H_{0}\right)$, logo concluiu-se que o melhor modelo a ser estimado é o de Dados em Painel de Efeito Fixo.

Conforme apresentado na Tabela 3, as variáveis população e dummies foram significativas para explicar a imprecisão orçamentária dos municípios em relação às receitas e despesas totais. O coeficiente da população foi significativo ao nível de 5\% de significância para as receitas, o que permite inferir que, havendo um aumento na população dos municípios em 1 unidade, a imprecisão na receita é acrescida em $\mathrm{R} \$ 4.547,81$. Por sua vez, no caso das despesas, a imprecisão também aumenta em torno de $\mathrm{R} \$ 5.736,40$ a cada 1 unidade acrescida à população. No caso das dummies o nível de significância é de $1 \%$, contribuindo também para o aumento da imprecisão, quanto menor a nota do I-Planejamento e I-Fiscal da cidade, maior é a imprecisão.

Speeden e Perez (2020) destacam que o número da população de um território impacta na qualidade do planejamento orçamentário e que esta pode estar relacionada com a imprecisão orçamentária. Aquino e Azevedo (2015) corroboram com a ideia e descrevem que, a realidade das grandes cidades é diferenciada dos pequenos municípios e que provavelmente os de pequeno porte carecem de estrutura de planejamento no sentido de não possuir um corpo técnico capacitado para realizar os ciclos do planejamento orçamentário (PPA, LDO e LOA).

Os resultados de Alves e Lee (2019), mesmo que em outra perspectiva sobre o IEGM, evidenciaram que o I-Fiscal teve significância positiva, porém, o mesmo não aconteceu com o I-Planejamento. Em outro ponto, os resultados de Araujo et al. (2021) apresentaram significância positiva diante de todas as variáveis independentes da amostra e ressaltaram que o IEGM possui relação significativa e necessária para o crescimento da efetividade dos municípios brasileiros.

Na Tabela 3 são evidenciados os resultados da estimação do modelo de dados em painel para efeitos fixos:

Tabela 3: Resultado do modelo de painel de efeitos fixos receitas e despesas totais.

\begin{tabular}{ccc}
\hline Variável & Receita & Despesa \\
\hline População & $4.547,81 * *$ & $5.736,40 * * *$ \\
& $(2.103,58)$ & $(1.982,78)$ \\
\hline Pib per capita & $639,44 \mathrm{NS}$ & $633,65 \mathrm{NS}$ \\
& $(775,89)$ & $(731,33)$ \\
\hline D. I-Plan/I-Fisc. & $4.550 .696,00 * * *$ & $3.628 .007,00 * * *$ \\
& $(1.254 .225,00)$ & $(1.182 .200,00)$ \\
\hline Constante & $-73.700 .000,00 *$ & $-93.300 .000,00 * * *$ \\
& $(37.600 .000,00)$ & $(35.400 .000,00)$ \\
\hline
\end{tabular}

Fonte: Elaborada pelos autores com base nos dados obtidos junto ao IBGE, TCEMG e IEGM-TCEMG. Nota: *** significância a 1\%; ** significância a 5\%; * significância a 10\%; NS : não significativa. D. I-Plan/I-Fisc.:dummies I-Planejamento e I-Fiscal são índices que compõem o IEGM-TCEMG.

A variável PIB per capita que foi inserida no modelo, não foi significativa para explicar a imprecisão orçamentária das receitas e despesas totais dos 34 municípios observados. As prováveis causas podem estar relacionadas com a baixa variação da arrecadação destes municípios, uma vez que, maioria das cidades é considerada de pequeno porte e gera economia através do agronegócio, da agricultura familiar e do comércio local que é limitado, fazendo com que a população recorra aos municípios de médio porte ou no e-commerce para realizar compras mensais ou eventualmente.

A imprecisão orçamentária, segundo Rezende e Cunha (2013), impacta diretamente no equilíbrio e na previsibilidade do orçamento público e indiretamente na compreensão e na vitalidade democrática dos instrumentos orçamentários. Azevedo (2013) aponta sobre a assimetria existente entre sociedade e os poderes executivo e legislativo que, por sua vez, se distanciam também.

Não obstante, é possível admitir que municípios que apresentam um menor grau de imprecisão no orçamento público 
favorecem a consolidação da democracia por fortalecer a confiança da sociedade com os poderes executivo e legislativo, sugere uma maior capacidade técnica da administração pública na GFP municipal, evitando assim, subestimações ou superestimações no orçamento e na execução de gastos não previstos e reduzindo o incrementalismo da gestão.

\section{Conclusão}

Esta pesquisa objetivou verificar a imprecisão orçamentária entre as estimativas e arrecadação de receitas e despesas públicas dos municípios das Regiões Imediatas de Teófilo Otoni e Águas Formosas - MG entre os exercícios financeiros de 2013-2018 e classificá-las segundo a sua efetividade. As dificuldades em cumprir o programado no planejamento orçamentário dos municípios brasileiros são explicadas por diversos fatores, como por exemplo: a população e PIB per capita utiliza dos como variáveis neste estudo. Normalmente, os gestores municipais elaboram orçamentos para além da sua capacidade de arrecadação de receitas, e gastam mais que o previsto, gerando o descumprimento da LOA e a não execução dos programas que deveriam equilibrar a gestão financeira no final de cada exercício.

O Plano Plurianual (PPA), a Lei de Diretrizes Orçamentárias (LDO) e a Lei Orçamentária Anual (LOA), são de grande importância para uma gestão financeira efetiva, outro fator de complementação para um bom planejamento é o IPlanejamento e I-Fiscal, conforme utilizados neste estudo como dummies. Onde foi constatado que a maior parte dos municípios tem um planejamento em fase de adequação como mostrado no ano de 2018, chegando em 70\% e apenas 3,13\% são altamente efetivos e muito efetivo em 2017 e 14,71\% efetivos e 14,71\% com baixo nível de adequação em 2018. No caso do I-Fiscal, não houve notas para altamente efetivo ou muito efetivo para nenhum dos municípios em todos os anos, porém em 2018 32,35\% dos municípios tiveram uma gestão fiscal considerada efetiva e 38,24\% foi considerada em fase de adequação e $29,41 \%$ considerada com baixo nível de adequação.

Quanto ao porte dos municípios, foi possível concluir que a região que compõe as zonas imediatas de Teófilo Otoni e Águas Formosas é formada, em sua maioria, por municípios de pequeno porte, representando aproximadamente 56\% do total de municípios. O restante da região é composta por municípios considerados médios ou muito pequenos, sendo representados na ordem de $20 \%$ e $24 \%$, respectivamente. A avaliação, aplicando o método PEFA, revelou que, ao considerar as receitas e despesas totais previstas e realizadas, os municípios investigados, em sua maioria, receberam classificação "D", visto que essa é a pior nota do programa, sendo possível perceber que a imprecisão para as receitas foi maior que para as despesas.

Dentro do modelo analisado em dados em painel e de efeitos fixos no Stata, as variáveis população e dummies se mostraram significantes para explicar a imprecisão orçamentária dos municípios apresentando uma relação positiva, tanto para as receitas, quanto para as despesas.

Esta pesquisa possui algumas limitações, como um período de tempo um pouco curto, principalmente nas avaliações do I-Planejamento e I-Fiscal, informações do ano de 2013 acerca das receitas e despesas que não estão no portal do TCE-MG, sendo necessário solicitar por e-mail. Para a variável PIB per capita as informações são existentes apenas até 2018, o que dificulta a ampliação para anos seguintes. No entanto, é sugestivo para pesquisas futuras aumentar o número de variáveis que possam explicar as diversas causas para a imprecisão orçamentária dos municípios analisados, como as receitas tributárias, receitas correntes e receitas patrimoniais, do mesmo modo, para as despesas, como gastos nas áreas da saúde, educação e na execução de obras civis. Assim, como ampliar o número de municípios, o período, aumentar as regiões ou mesmo para todos os municípios de Minas Gerais. 


\section{Referências}

Alves, F. I. A. B., \& Lee, S. F. (2019). Gestão pública: uma análise dos municípios Cearenses quanto ao índice de efetividade da gestão municipal (IEGM). Revista Contribuciones a las Ciencias Sociales, (mayo 2019). En línea: https://www.eumed.net/rev/cccss/2019/05/efetividade-gestao-municipal.html

Alves, G. H. T. (2015). O Orçamento Federal entre a realidade e a ficção: um desafio à transparência da despesa pública no Brasil. Rev. da CGU - Brasília 7(11): 128-154, jul/dez.

Aquino, A. C. B. de, \& Azevedo, R. R. de. (2015). O "IR" realismo orçamentário nos municípios brasileiros. Business and Management Review, 5(1), 210224. http://www.businessjournalz.org/Brazil\%20Special\%20Edition/SI\%20June,\%202015/BMR(00571)-V5-N01-June-2015-SI-VIII-19.pdf

Araujo et al., (2021). Gestões municipais no Brasil: um estudo a partir do índice de efetividade das gestões municipais - IEGM. Revista Catarinense da Ciência Contábil, ISSN 2237-7662, Florianópolis, SC, v. 20, 1-17, e3137. 10.16930/2237-7662202131371

Azevedo, R. R. de. (2013). Imprecisão na Estimação Orçamentária dos Municípios Brasileiros. Ribeirão Preto. USP. Dissertação. Mestrado. Faculdade de Economia, administração e Contabilidade de Ribeirão Preto/USP. https://www.teses.usp.br/teses/disponiveis/96/96133/tde-17032014-110156/pt-br.php

Azevedo, R. R. de, \& Aquino, A. C. B. de. (2016). O planejamento em municípios de pequeno porte em São Paulo. Revista de Contabilidade e Organizações, 10(26), 63-76. https://doi.org/10.11606/rco.v10i26.111202

Bairral, M. A. da C., Silva, A. H. C., \& Alves. F. J. dos S. (2015). Transparência no setor público: uma análise dos relatórios de gestão anuais de entidades públicas federais no ano de 2010. Revista de Administração Pública, 49(3), 642 a 675

Baldissera, J. F., Dall'Asta, D., Casagrande, L. F., \& Oliveira, A. M. B. de. (2020). Influência dos aspectos socioeconômicos, financeiro-orçamentários epolítico-eleitorais na transparência dos governos locais. Revista de Administração Pública, 54(2), 340-359. https://doi.org/10.1590/0034-761220190048

Baldo, R. A. (2018). Democratização do Orçamento Público pela legalidade, legitimidade e economicidade. Rev. Bras. Políticas Públicas. Brasília. 8(1). 689705

Belline, E. C. de O., Silva, A. C. B. da., Albuquerque, F. dos S., \& Silva. V. da. (2017). Transparência Pública, Um Caminho Sem Volta: Descrição das informações que devem constar nos portais governamentais. Id onLine Revista Multidisciplinar Psicologia, 11 (37). 80-102. https://doi.org/10.14295/idonline.v11i37.808

Brasil. (2000). Lei Complementar n. 101. Estabelece normas de finanças públicas voltadas para a responsabilidade na gestão fiscal e dá outras providências. http://www2.senado.leg.br/bdsf/handle/id/70313

Brasil. (2021). Ministério da Economia. Secretaria Especial da Fazenda. Secretaria de Orçamento Federal. - Manual Técnico de Orçamento MTO 2022. https://www1.siop.planejamento.gov.br/mto/lib/exe/fetch.php/mto2022:mto2022-versao7.pdf

Boneti, L.W. (2018). Políticas públicas por dentro. (4a ed.), editora Unijuí.

Carneiro, B. de O. (2018). Uma proposta de avaliação da governança na gestão orçamentária dos estados brasileiros. Dissertação. Mestrado. Universidade Federal do Ceará. Fortaleza. http://repositorio.ufc.br/handle/riufc/37883

Corrêa, V. L. A. (2004). Gerenciamento eficaz dos processos de contratações. In S. C. Vergara., \& V. L. A. Corrêa (Eds.), Propostas para uma Gestão Pública Municipal Efetiva: Instrumentos e mecanismos para uma gestão municipal eficiente. (2 ed., pp. 151-166). FGV.

Costa, F. L., \& Cunha, A. P. G. (2004). Pensar o desenvolvimento a partir do local: novo desafio para os gestores públicos. In S. C. Vergara., \& V. L. A. Corrêa (Eds.), Propostas para uma Gestão Pública Municipal Efetiva: A gestão estratégica do município. (2 ed., pp. 69-88). FGV.

Cunha, A., \& Resende, F. (2005). Orçamento e desenvolvimento. In B. S. Cavalcanti, M. A. Ruediger, \& R. Sobreira (Eds.), Desenvolvimento e construção nacional: políticas públicas (1 ed., pp. 57-72). FGV.

Cruz, M. do C. M. T., Silva, T. A. B., \& Spinelli, M. V. (2016). O papel das controladorias locais no cumprimento da Lei de Acesso à Informação pelos municípios brasileiros. Cad. EBAPE.BR, Rio de Janeiro, 14(3), 721-743. http://dx.doi.org/10.1590/1679-395131556

Dias, L. N. da S., Aquino, A. C. B. de., Silva, P. B. da, \& Albuquerque, F. dos S. (2020). Terceirização de portais de transparência fiscal em prefeituras municipais. Revista de Contabilidade e Organizações, v. 14, p. e164383

Fajardo, B. de A. G. (2016). Vieses orçamentários em entes subnacionais: uma análise sob a ótica da estimação das receitas estaduais. Tese (Pós-Doutorado em Administração) -Escola Brasileira de Administração Pública e de Empresas, Fundação Getúlio Vargas- FGV, Rio de Janeiro.

Fiirst, C., Pamplona, E., Hein, N., \& Zonatto, V. C. da S. (2017). Eficiência de previsibilidade orçamentária da receita pública: um estudo em municípios do Estado do Paraná entre os exercícios 2002 e 2013. RACE, Revista de Administração, Contabilidade e Economia, $16(3)$, 983-1008. https://doi.org/10.18593/race.v16i3.11537

Gil, A. C. (2008). Métodos e técnicas de pesquisa social(6. ed.). São Paulo: Atlas.

Greene, W. H. (2002). Econometric analysis. Fifth edition. New York University. Upper Saddle River, New Jersey 07458.

Gujarati, D. N. (2006). Econometria Básica. Tradução Maria José Cyhlar Monteiro. Rio de Janeiro: Editora Elsevier.

Gujarati, D., \& Porter D. C. (2011). Econometria Básica. (5ª . ed.). Editora AMGH Ltda.

Hausman, J. A. (1978). Specification tests in Econometrics. The Econometrics Society, 46(6), 1251-1271. 
Instituto Brasileiro de Geografia e Estatística - IBGE. (2021). https://www.ibge.gov.br/estatisticas/economicas/contas-nacionais/9088-produto-interno-brutodos-municipios.html?edicao $=29720 \& \mathrm{t}=$ resultados

Instituto Brasileiro de Geografia e Estatística - IBGE. (2017). Divisão regional do Brasil em regiões geográficas imediatas e regiões geográficas intermediárias:Coordenação de Geografia. - Rio de Janeiro : IBGE.

Instituto Rui Barbosa. Anuário do IEGM Brasil. (2015). Belo Horizonte. http://iegm.irbcontas.org.br/base/anuario_2015.pdf

Instituto Rui Barbosa. Ranking do IEGM Brasil. (2015). Belo Horizonte. https://www6.tce.ma.gov.br/iegm_util/rankingTabelas.zul?sigla=MG\&ano=2015

Marconi, M. de A., \& Lakatos, E. M. (2003). Fundamentos de metodologia científica (5. ed.). São Paulo:Atlas.

Marques Junior, L. dos S. (2018). Processo orçamentário, previsões orçamentárias e os desvios de execução no RS. Revista Estudos de Planejamento. n.18. p. 121-143. https://revistas.dee.spgg.rs.gov.br/index.php/estudosplanejamento/article/view/4301/4059

Melo, H. P. de., \& Morandi, L. (2020). Uma análise da distribuição do PIB per capita entre mulheres e homens no Brasil, 1991-2015. Revista de Economia Contemporânea (2021) 25(1): p. 1-23. http://dx.doi.org/10.1590/198055272515

Motta, P. R. (2004). Gestão estratégica. In S. C. Vergara., \& V. L. A. Corrêa (Eds.), Propostas para uma Gestão Pública Municipal Efetiva: A gestão estratégica do município. (2 ed., pp. 47-67). FGV.

Oliveira, C. L. de, \& Ferreira; F. G. B. de C. (2017). O Orçamento Público no Estado Constitucional Democrático e a Deficiência Crônica na Gestão das Finanças Públicas no Brasil. Sequência. 38(76). 183-212. http://dx.doi.org/10.5007/2177-7055.2017v38n76p183

Paludo, A. V. (2013). Orçamento público e administração financeira e orçamentária e LRF. (4a ed.), Elsevier.

Passos, G. O., \& Amorim, A. de C. (2018). A Construção do Índice de Efetividade da Gestão Municipal (Iegm). Rev. FSA, Teresina, 15(6), art. 14, 241259, nov./dez. http://dx.doi.org/10.12819/2018.15.6.14

Pereira, A. S., Shitsuka, D. M., Parreira, F. J., \& Shitsuka, R. (2018). Metodologia da pesquisa científica - (1ª ed.): UFSM, NTE.

Pinto, N. G. M., \& Coronel, D. A. (2017). Eficiência e eficácia na administração: proposição de modelos quantitativos. Revista Unemat de Contabilidade. $6(11)$.

Piza, E. C. (2016). Política fiscal, previsões orçamentárias e os determinantes dos desvios de execução no Brasil. Tese de Doutorado, Faculdade de Economia, Administração e Contabilidade, Universidade de São Paulo, São Paulo.

Quadro de Avaliação da Gestão das Finanças Públicas. (2019). Segunda Edição. Secretariado PEFA. 1818 H Street NW.Washington DC 20433, EUA.

Resende, F., \& Cunha, A. (2013). A reforma esquecida: Orçamento, Gestão Pública e desenvolvimento. Rio de Janeiro. Ed. FGV.

Rodrigues, G. (2010). Partidos políticos e gastos públicos em Santa Catarina: A influência das ideologias partidárias nas decisões de investimentos. Tese de Doutorado, Universidade Federal de Santa Catarina, Florianópolis, Santa Catarina.

Santos, F. R. Dos., Moreira C. J., A. R., Gonçalves de O. A., \& Ishikawa R, V. (2017). O orçamento-programa e a execução das políticas públicas. Revista Do Serviço Público, 68(1), 191 - 212. https://doi.org/10.21874/rsp.v68i1.1038

Speeden, E. A., \& Perez, O. C. (2020). Fatores que impactam na qualidade do planejamento orçamentário dos municípios do estado de São Paulo. Administração Pública E Gestão Social. https://doi.org/10.21118/apgs.v12i1.5517

Teixeira, R. R., Dias, C. A., Santos, C. M., \& Barros, G. F. (2021). Technical and legal instruments to support the adoption of the public expenditure and financial responsibility program (PEFA) in the evaluation of municipal public finance management. Research, Society and Development, $10(4)$, e4010413663. https://doi.org/10.33448/rsd-v10i4.13663

Tribunal de Contas do Estado de Minas Gerais - MG. (2021). Fiscalizando com o TCE Minas Transparente. https://fiscalizandocomtce.tce.mg.gov.br/\#/inicio

Tribunal de Contas do Estado de Minas Gerais - MG. (2019). Manual do Índice de Efetividade da Gestão Municipal TCEMG. https://fiscalizandocomtce.tce.mg.gov.br/\#/public/iegm

Valle, V. L. do. (2018). Planejamento Orçamentário e Políticas Públicas: explorando uma alternativa de reconciliação pela indução. Revista de Investigações Constitucionais. Curitiba. 5(2)., 113-134. 10.5380/rinc.v5i2.55250.

Vieira, M. A. (2016). Planejamento dos gastos públicos: O caso dos departamentos didáticos da Universidade Federal de Santa Maria. Santa Maria. Dissertação. Mestrado. Centro de Ciências Sociais e Humanas.

Zielinski, C. F., Hirt, J. de F., \& Witt, C. (2017). Nível de imprecisão orçamentária dos municípios da região da Amsulep. Revista Brasileira de Contabilidade. 223, 33-43, https://docplayer.com.br/112685997-Nivel-de-imprecisao-orcamentaria-dosmunicipios-da-regiao-da-amsulep.html 